\title{
Successful bailout of stent graft stuck in stent occlusion lesion
}

\author{
Tamon Kato $^{1}$ (1) $\cdot$ Ayumu Nagae $^{1} \cdot$ Takahiro Sakai $^{1} \cdot$ Tatsuya Saigusa $^{1} \cdot$ Soichiro Ebisawa ${ }^{1} \cdot$ Koichiro Kuwahara $^{1}$
}

Received: 19 June 2020 / Accepted: 6 August 2020 / Published online: 25 August 2020

(c) The Author(s) 2020

VIABAHN $^{\circledR}\left(\right.$ VIABAHN $^{\circledR}$, W. L. Gore, Flagstaff, AZ, USA) is a safe and effective stent graft for the treatment of peripheral artery disease, especially for very long occlusions and thrombotic lesions $[1,2]$. VIABAHN ${ }^{\circledR}$ has an unfolding stored thread delivery system, which carries a risk of imperfections that can catch on a lesion or other structures. Cases of devices becoming stuck before deployment are considered serious events that may need surgical repair.

A 69-year-old man with a 7-year history of hemodialysis for diabetic nephropathy received coronary artery bypass surgery 3 years prior. He first presented at our hospital 2 years ago complaining of right ischemic foot ulceration and right SFA occlusion. We implanted VIABAHN ${ }^{\circledR}$. One year later, he returned with right SFA re-occlusion. We implanted a bare-metal nitinol stent $\left(\right.$ INNOVA $^{\circledR}$ $7.0 \mathrm{~mm} \times 100 \mathrm{~mm}$, Boston Scientific, MA, USA) in the reoccluded VIABAHN ${ }^{\circledR}$ site. Nine months later, he exhibited yet another right foot ulcer.

Pre-procedural angiography showed re-occlusion in the right SFA from the ostium to the popliteal artery (Fig. 1a) and a stent fracture site (Fig. 1b) in spite of continued dual antiplatelet therapy (aspirin $100 \mathrm{mg}$ and clopidogrel $75 \mathrm{mg}$ ). His ankle-brachial index was 0.57 .

We employed a crossover approach from the left common femoral artery with a 6 Fr Destination ${ }^{\circledR}$ (TERUMO Co., Tokyo, Japan). Next, we attempted wiring with a Prominent ${ }^{\circledR}$ microcatheter (TOKAI Medical Products, Aichi, Japan) and Halberd ${ }^{\circledR}$ (ASAHI INTECC CO LTD, Aichi, Japan), with aspiration and distal protection using TOMETAKUN $^{\circledR}$ (ZEON MEDICAL INC, Tokyo, Japan). Intravascular ultrasound (IVUS; Eagle Eye ${ }^{\circledR}$, Volcano Philips, CA, USA) showed a partial stent fracture (Fig. 1c).
Repeated balloon angioplasty with a $4.0 \mathrm{~mm}$ SABER ${ }^{\circledR}$ (Cordis, Cardinal Health, OH, USA) and aspiration was not effective. We next tried to insert VIABAHN ${ }^{\circledR}$ into the stent. We felt strong resistance during stent placement as the VIABAHN ${ }^{\circledR}$ became stuck at the stent fracture site (Fig. 1d), possibly due to deployment line interference. Antegrade wiring from the brachial artery with a $6 \mathrm{Fr}$ system could not pass the stuck site. Next, we attempted a retrograde approach with a $4 \mathrm{Fr}$ sheath in the popliteal artery. Although neither a Jupiter ${ }^{\circledR} 60$ DP (Boston Scientific, MA, USA) nor a 0.035 Radifocus ${ }^{\circledR}$ (TERUMO Co., Tokyo, Japan) could be passed, we were able to penetrate a new VIABAHN ${ }^{\circledR}$ with a Radifocus ${ }^{\circledR}$ wire tail from distal to proximal (Fig. 1e). We changed to a Vassallo ${ }^{\circledR}$ (Cordis, Cardinal Health, OH,USA) with NAVICROSS ${ }^{\circledR}$ (TERUMO Co., Tokyo, Japan) and subsequently performed balloon dilatation with a $4 \mathrm{~mm} \times 20 \mathrm{~mm}$ Coyote ${ }^{\circledR}$ (Boston Scientific, MA, USA) for the previous fracture stent and stuck point with a newly deployed VIABAHN ${ }^{\circledR}$ (Fig. 1f). IVUS showed that the wire had penetrated the stent graft. After balloon dilatation with a $5.0 \mathrm{~mm} \times 40 \mathrm{~mm}$ SABER $^{\circledR}$ (Cordis, Cardinal Health, OH, USA), the resistance disappeared and we could implant the VIABHN ${ }^{\circledR}$ into the previous stent. We completed full coverage of the re-occlusion site and post-ballooning (Fig. 1g).

The retrograde tail of 0.035 wire penetration and balloon dilation are viable options for bailout of VIABAHN ${ }^{\circledR}$ stuck.

Acknowledgement We would like to thank Trevor Ralph for English language editing.

Tamon Kato

katot20110408@gmail.com

1 Department of Cardiovascular Medicine, Shinshu University School of Medicine, 3-1-1 Asahi, Matsumoto, Nagano 390-8621, Japan 


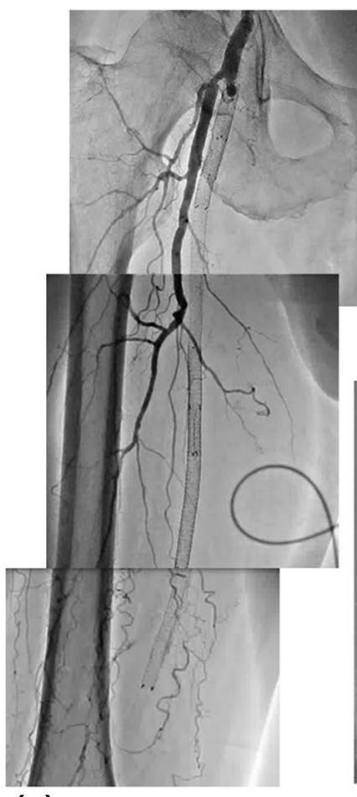

(a)

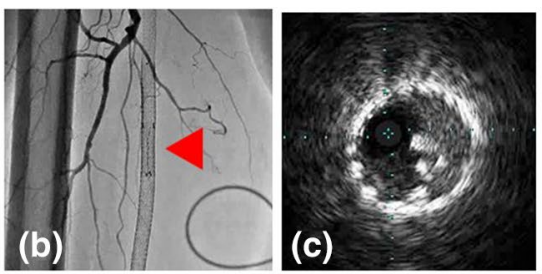

(c)
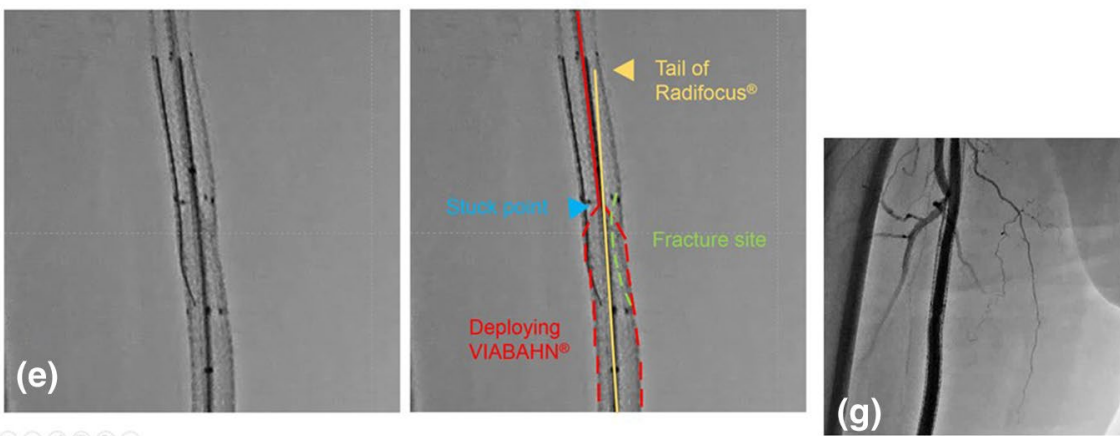

Fig. 1 a Pre-procedure angiography: re-occlusion from ostium to distal SFA. b Stent fracture site (bare metal nitinol stent in VIABAHN ${ }^{\circledR}$ 9 months prior). c IVUS findings: stent fracture site. d VIABAHN ${ }^{\circledR}$

\section{Compliance with ethical standards}

Conflict of interest All authors have no competing interests.

Open Access This article is licensed under a Creative Commons Attribution 4.0 International License, which permits use, sharing, adaptation, distribution and reproduction in any medium or format, as long as you give appropriate credit to the original author(s) and the source, provide a link to the Creative Commons licence, and indicate if changes were made. The images or other third party material in this article are included in the article's Creative Commons licence, unless indicated otherwise in a credit line to the material. If material is not included in the article's Creative Commons licence and your intended use is not permitted by statutory regulation or exceeds the permitted use, you will need to obtain permission directly from the copyright holder. To view a copy of this licence, visit http://creativecommons.org/licenses/by/4.0/. stuck in stent fracture site. e Penetration of stent graft with tail of Radifocus ${ }^{\circledR}$ from retrograde. f Ballooning of stuck site. g Final angiography

\section{References}

1. McQuade K, Gable D, Pearl G, Theune B, Black S. Four-year randomized prospective comparison of percutaneous ePTFE/nitinol self-expanding stent graft versus prosthetic femoral-popliteal bypass in the treatment of superficial femoral artery occlusive disease. J Vasc Surg. 2010;52:584-90.

2. Zeller T, Peeters P, Bosiers M, Lammer J, Brechtel K, Scheinert $\mathrm{D}$, et al. Heparin-bonded stent-graft for the treatment of TASC II C and D femoropopliteal lesions: the Viabahn- $25 \mathrm{~cm}$ trial. J Endovasc Ther. 2014;21:765-74.

Publisher's Note Springer Nature remains neutral with regard to jurisdictional claims in published maps and institutional affiliations. 